\title{
Volatility Forecasting for Risk Management
}

\author{
CHRIS BROOKS $^{1 *}$ AND GITA PERSAND ${ }^{2}$ \\ 1 ISMA Centre, University of Reading, UK \\ ${ }^{2}$ Department of Economics, University of Bristol, UK
}

\begin{abstract}
Recent research has suggested that forecast evaluation on the basis of standard statistical loss functions could prefer models which are sub-optimal when used in a practical setting. This paper explores a number of statistical models for predicting the daily volatility of several key UK financial time series. The out-of-sample forecasting performance of various linear and GARCH-type models of volatility are compared with forecasts derived from a multivariate approach. The forecasts are evaluated using traditional metrics, such as mean squared error, and also by how adequately they perform in a modern risk management setting. We find that the relative accuracies of the various methods are highly sensitive to the measure used to evaluate them. Such results have implications for any econometric time series forecasts which are subsequently employed in financial decision making. Copyright (c) 2003 John Wiley \& Sons, Ltd.
\end{abstract}

KEY WORDS internal risk management models; asset return volatility; Value at Risk models; forecasting; univariate and multivariate GARCH models

\section{INTRODUCTION}

Modelling and forecasting stock market volatility has been the subject of a great deal of debate over the past fifteen years or so. Volatility, usually measured by the standard deviation of portfolio returns, is uniquely important in financial markets, for it is often taken to represent the portfolio's risk. Consequently, the literature on forecasting volatility is sizeable and still growing. Akgiray (1989), for example, finds the GARCH model superior to $\mathrm{ARCH}$, exponentially weighted moving average, and historical mean models for forecasting monthly US stock index volatility. A similar result concerning the apparent superiority of GARCH is observed by West and Cho (1995) using onestep-ahead forecasts of dollar exchange rate volatility, evaluated using root-mean squared prediction errors. However, for longer horizons, the model behaves no better than their alternatives. ${ }^{1}$ Also using

\footnotetext{
* Correspondence to: Chris Brooks, ISMA Centre, PO Box 242, University of Reading, Whiteknights, Reading RG6 6BA, UK. Email: c.brooks@rdg.ac.uk

${ }^{1}$ The alternative models are the long-term mean, IGARCH, autoregressive models, and a non-parametric model based on the Gaussian kernel.
} 
the same models and data, West et al. (1993) use asymmetric, utility-based criteria for evaluating the conditional variance forecasts, finding that GARCH models tend to yield the highest utilities. Pagan and Schwert (1990) compare GARCH, EGARCH, Markov switching regime and three nonparametric models for forecasting monthly US stock return volatilities. The EGARCH followed by the GARCH models perform moderately; the remaining models produce very poor predictions. Franses and van Dijk (1996) compare three members of the GARCH family (standard GARCH, QGARCH and the GJR model) for forecasting the weekly volatility of various European stock market indices. They find that the non-linear GARCH models were unable to beat the standard GARCH model. Brailsford and Faff (1996) find GJR and GARCH models slightly superior to various simpler models ${ }^{2}$ for predicting Australian monthly stock index volatility. The conclusion arising from this growing body of research is that forecasting volatility is a 'notoriously difficult task' (Brailsford and Faff, 1996, p. 419), although it appears that conditional heteroscedasticity models are among the best that are currently available. In particular, more complex non-linear and non-parametric models are inferior in prediction to simpler models, a result echoed in an earlier paper by Dimson and Marsh (1990) in the context of relatively complex versus parsimonious linear models. Finally Brooks (1998) uses a measure of market volume in volatility forecasting models, but observes no increase in forecasting power.

Recent papers have also sought to compare the predictive ability of volatility forecasts derived from the market prices of traded options, with those generated using econometric models (see, for example, Heynen and Kat, 1994 or Day and Lewis, 1992). The general consensus appears to be that implied volatility forecasts are more accurate than those derived using pure time series analysis, but also that the latter still contain additional information not embedded in the implied values.

Also over the past decade, there has been rapid development of techniques for measuring and managing financial risk, partially motivated by a spate of recent financial disasters involving derivative securities. One of the most popular approaches to risk measurement is by calculating what is known as an institution's 'Value at Risk' (VaR). Broadly speaking, Value at Risk is an estimation of likely losses which could arise from changes in market prices. More precisely, it is defined as the money-loss in a portfolio that is expected to occur over a pre-determined horizon and with a pre-determined degree of confidence. The roots of VaR's popularity stem from the simplicity of its calculation, its ease of interpretation, and from the fact that VaR can be suitably aggregated across an entire firm to produce a single number which broadly encompasses the risk of the positions of the firm as a whole. Jorion (1996) or Dowd (1998) provide thorough introductions to VaR, and Brooks and Persand (2000a,b) present recent discussions of VaR model estimation issues. The value at risk estimate is also often known as the position risk requirement or minimum capital risk requirement (MCRR); we shall use the three terms interchangeably in the exposition below.

Although the academic literature has thus far failed to keep pace with this expansion, evidenced by the relatively few academic studies that address this topic, one exception is the study by Jackson et al. (1998), which assesses the empirical performance of various models for VaR using historical returns from the actual portfolio of a large investment bank. They find that nonparametric, simulation-based techniques yield more accurate measures of the tail probabilities than parametric models. Alexander and Leigh (1997) offer an analysis of the relative performance of equally weighted, exponentially weighted moving average (EWMA), and GARCH model forecasts of volatility, evaluated using traditional statistical and operational adequacy criteria. The GARCH

${ }^{2}$ The other models employed are the random walk, the historical mean, a short- and a long-term moving average, exponential smoothing, an exponentially weighted moving average model, and a linear regression. 
model is found to be preferable to EWMA in terms of minimizing the number of exceedences in a backtest, although the simple unweighted average is superior to both. Brooks et al. (2002) investigate the effectiveness of various hedging models when assessed according to their ability to minimize VaR, finding that there is a large role for time-varying volatilities and correlations, but a very minor role for asymmetries.

This paper seeks to combine and advance the two literatures in volatility forecasting and financial risk management in a number of ways. First, the volatility forecasting debate is re-opened, and the forecasts from the various models evaluated on the basis of how well they perform in a modern risk management setting, as well as by traditional statistical loss functions. This is important for Dacco and Satchell (1999) demonstrate that the evaluation of forecasts from non-linear models using statistical measures can be misleading, and they propose the use of alternative economic loss functions. Here, the relative performances of the forecasting models are evaluated using both statistical and economic loss functions, so that a comparison can be drawn between the two. Second, we also directly compare the forecasting performance of univariate and multivariate forecasting models for financial asset return volatility. Multivariate GARCH models permit the estimation of the conditional covariances between assets' returns, and explicit modelling of this interaction may improve the accuracy of forecasts of volatility for a portfolio comprising these components. Finally, we evaluate forecasts over the 1- 5-, 10- and 20-day horizons. Although many volatility forecasting papers compare accuracies at daily horizons, it is often the case that financial market practitioners require predictions of much lower frequency. For example, the Basle Committee on Banking Supervision rules for the use of VaR models (see, for example, Basle Committee on Banking Supervision, 1998) require the use of a 10-day holding period, which allows reasonable time for investors to unwind a position, and fund managers typically re-balance their portfolios on a monthly (20 trading days) basis.

The remainder of the paper is organized as follows. The next section presents the data employed in the study, while the forecasting models are described briefly in the third section. Forecast evaluation methods are outlined and discussed in the fourth section with results given in the fifth section. The final section summarises the paper, and offers some concluding remarks.

\section{THE DATA}

In this study we calculate the VaRs for three different assets-the FTSE All Share Total Return Index, the FTA British Government Bond (over 15 years) Index and the Reuters Commodities Price Index, as well as an equally weighted portfolio containing these three assets. ${ }^{3,4}$ The data were collected from Datastream International, and spans the period 1 January 1980 to 25 March 1999. Observations corresponding to UK public holidays were deleted from the data set to avoid the incorporation of spurious zero returns, leaving 4865 observations, or trading days in the sample. In the empirical work below, we use the daily log return of the original indices. Summary statistics for the data are given in Table I. It is evident that the FTSE returns series is the most volatile,

\footnotetext{
${ }^{3}$ Our analysis assumes that we are long all the three assets - both individually and in the portfolio. A similar analysis could be undertaken for short or netted positions, but we would not expect our conclusions to be markedly altered.

${ }^{4}$ This portfolio is deliberately highly simplistic relative to a genuine bank's book, as well as being entirely linear in nature. The use of a simple portfolio enables us to more easily unravel the various estimation issues and broad aspects of the methodologies. Additionally, the three series that we consider are all fundamental or 'benchmark' factor series, to which other series are mapped under the JP Morgan approach.
} 
Table I. Summary statistics

\begin{tabular}{lcccc}
\hline & Long Govt Bond & FTSE All Share & Reuters Commodities & Portfolio \\
\hline Mean & 0.000233 & 0.000301 & -0.000219 & 0.000171 \\
Variance & $6.50 \times 10^{-6}$ & $1.410 \times 10^{-5}$ & $6.210 \times 10^{-6}$ & $3.691 \times 10^{-6}$ \\
Skewness & 0.0132 & $-1.063^{* *}$ & $-0.5663^{* *}$ & $-0.291^{* *}$ \\
Kurtosis & $3.37^{* *}$ & $14.654^{* *}$ & $18.369^{* *}$ & $4.446^{* *}$ \\
Bera-Jarque Statistic & $2300^{* *}$ & $44400^{* *}$ & $68700^{* *}$ & $4080^{* *}$ \\
\hline
\end{tabular}

Notes: The Bera-Jarque statistic is distributed asymptotically as a $\chi^{2}(2)$ under the null of normality. ${ }^{*}$ and ${ }^{* *}$ indicate significance at the $5 \%$ and $1 \%$ levels respectively.

while the government bond index returns is the least. The benefits from diversification, in terms of a substantial reduction in variability, are clear, since the variance for the equally weighted portfolio returns is almost half that of the least volatile component. Also, as one might anticipate, the series are all strongly non-normal. All are leptokurtic, while the FTSE All-Share and commodities series are also significantly skewed to the left.

\section{FORECASTING VOLATILITY}

\section{Construction of forecasts and notation}

The total sample of 4865 observations is split into two parts: the first 1250 observations (approximately 5 years of daily trading data) are used for estimation of the parameters of the model, and then one-, two-,..., twenty-step-ahead forecasts are calculated. The multi-step-ahead forecasts are then aggregated to form forecasts of volatility over the next 5, 10, and 20 days. We can thus write 5

$$
\sigma_{t, N}^{2}=\sum_{n=1}^{N} \sigma_{t, t+n}^{2}
$$

where $\sigma_{t, N}^{2}$ denotes the time $t$ aggregated forecast for the next $N$ steps, and $\sigma_{t, t+n}^{2}$ denotes the $n$-step-ahead forecast made at time $t$.

In contrast to much previous research in this area, these are not one-, two-, three-. . . twenty-stepahead forecasts, but rather we aggregate the forecasts for the next 5, 10, and 20 days. Aggregated forecasts will be the ones of interest to financial market practitioners and risk managers, when they have investment horizons longer than one day; they will not be particularly interested in multi-stepahead one-day volatility forecasts, such as the volatility forecast for day $t+20$ made on day $t$. The sample is then rolled forward by removing the first observation of the sample and adding one to the end, and another set of forecasts of the next twenty days' volatilities is made, and aggregated. This 'recursive' modelling and forecasting procedure is repeated until a forecast for observation 4865 has been made using data available at time 4845. Computation of forecasts using a rolling window of data should ensure that the forecasts are made using models whose parameters have

\footnotetext{
${ }^{5}$ This step is permissible since the variances are additive over time. Another possibility would be to multiply the one-step-ahead forecast by the desired horizon using an equivalent of the 'square root of time' rule, so that, for example, the volatility forecast over the next 20 days is 20 times the forecast for tomorrow. However, our approach is likely to be superior, since it employs more information while implicit extrapolation of one-step forecasts could be inappropriate for a mean-reverting series.
} 
been estimated using a sufficient span of time, while not incorporating such old vintages that the data may no longer relevant in the context of an evolving financial market.

\section{Forecasting models}

Almost all of the forecasting models employed in this study are not new, rather it is the evaluation of the models which is novel. Hence the model descriptions are brief and presented in Table II, with $\sigma_{f, t+n}^{2} \mid \Omega_{t}$ denoting the $n$-step-ahead $(n=1,2, \ldots, 20)$ forecast for the conditional variance upon information available at time $t$, where $t$ runs from observation 1250 to 4845 . With one possible exception, the model equations in Table II are self-explanatory, and readers are referred to Bollerslev et al. (1992), Brailsford and Faff (1996), or Brooks (1998), and the references therein, for a more detailed treatment.

The only model which perhaps requires further explanation is the multivariate GARCH model, which has not been employed in previous studies of volatility forecast performance. The particular parameterization used here is of the diagonal VEC form due to Bollerslev, Engle, and Wooldridge (1988), where each element of the conditional variance covariance matrix $h_{j k, t}$ depends on past values of itself and past values of $\varepsilon_{j, t} \varepsilon_{j, t}^{\prime}$, which may be written

$$
\operatorname{vec}\left(H_{t+1}\right)=h_{t+1}=C_{0}+A_{1} \operatorname{vec}\left(\varepsilon_{t} \varepsilon_{t}^{\prime}\right)+B_{1} h_{t}
$$

where vec denotes the column stacking operator, $A_{1}$ and $B_{1}$ are restricted to be diagonal. The parameterization for $H_{t+1}$ conditional upon the information set allows each element of the conditional variance-covariance matrix to depend on lags of the squares and of the cross products of the elements of $\varepsilon_{t+1}$ as well as lags of the elements of $H_{t+1}$.

\section{EVALUATING VOLATILITY FORECASTS}

\section{Standard loss functions}

Three criteria are used here to evaluate the accuracy of the forecasts: mean squared error (MSE), mean absolute error (MAE), and proportion of over-predictions. Mean squared error provides a quadratic loss function which disproportionately weights large forecast errors more heavily relative to mean absolute error, and hence the former may be particularly useful in forecasting situations when large forecast errors are disproportionately more serious than small errors. The proportion of over-predictions should give a rough indication of the average direction of the forecast error (compared with the two previous measures which only give some measure of the average size) and whether the models are persistently over- or under-predicting the 'true' value of volatility. Hence this measure gives an approximate guide as to whether the forecasts are biased.

\section{But what is volatility?}

Unlike financial asset returns, volatilities are not directly observable from the market. Consequently, when attempting to benchmark the accuracy of volatility forecasting models, researchers are necessarily required to make an auxiliary assumption about how the ex post or realized volatilities are calculated. The vast majority of existing studies, including those listed in the introduction to this paper, use squared returns of the frequency of the data and analysis, as the measure of realized volatility. For example, studies using daily data would assume that the 'correct' volatility number 
Table II. Description of models used for forecasting

\begin{tabular}{|c|c|c|c|}
\hline Model & Acronym & Equations for model & Equation \\
\hline 1. Random walk in volatility & RW & $\sigma_{f, t+n}^{2}=\sigma_{t}^{2}$ & (2) \\
\hline 2. Long-term mean & LTM & $\sigma_{f, t+n}^{2}=\frac{1}{1250} \sum_{j=t-1249}^{t} \sigma_{t-j}^{2}$ & (3) \\
\hline 3. Short-term moving average & MA5 & $\sigma_{f, t+n}^{2}=\frac{1}{5} \sum_{j=0}^{4} \sigma_{t-j}^{2}$ & (4) \\
\hline 4. Long-term moving average & MA100 & $\sigma_{f, t+n}^{2}=\frac{1}{100} \sum_{j=0}^{99} \sigma_{t-j}^{2}$ & (5) \\
\hline 5. Linear regression with one lag & AR1 & $\sigma_{f, t+n}^{2}=\alpha_{0}+\alpha_{1} \sigma_{t}^{2}+\varepsilon_{t}$ & (6) \\
\hline 6. Linear regression with AIC lags & ARAIC & $\sigma_{f, t+n}^{2}=\beta_{0}+\sum_{j=0}^{p-1} \beta_{j} \sigma_{t-j}^{2}+\varepsilon_{t}$ & (7) \\
\hline 7. $\operatorname{GARCH}(1,1)$ & GAR & $\begin{array}{c}r_{t+1}=\mu+\varepsilon_{t+1}, \varepsilon_{t+1} \sim N\left(0, \sigma_{t+1}^{2}\right) \\
\sigma_{f, t+n}^{2}=\gamma_{0}+\varphi_{1} \varepsilon_{t}^{2}+\gamma_{2} \sigma_{t}^{2}\end{array}$ & (8) \\
\hline 8. $\operatorname{GJR}(1,1)$ & GJR & $\begin{array}{l}\sigma_{f, t+n}^{2}=\delta_{0}+\delta_{1} \varepsilon_{t}^{2}+\delta_{2} \sigma_{t}^{2}+\delta_{3} S_{t}^{-} \varepsilon_{t}^{2} \\
S_{t}^{-}=1 \text { for } \varepsilon_{t} \leq 0 \text { and } 0 \text { otherwise }\end{array}$ & (9) \\
\hline 9. $\operatorname{EGARCH}(1,1)$ & EGAR & $\log \left(\sigma_{f, t+n}^{2}\right)=\omega_{1}+\omega_{2} \log \left(\sigma_{t}^{2}\right)+\omega_{3} \frac{\varepsilon_{t}}{\sqrt{\sigma_{t}^{2}}}$ & (10) \\
\hline $\begin{array}{l}\text { 10. Long exponentially weighted } \\
\text { moving average }\end{array}$ & EMA5 & $\sigma_{f, t+n}^{2}=\left(1-\lambda_{1}\right) \sum_{t=1} \lambda_{1}^{t-1}\left(r_{t}-\bar{r}\right)$ & (11) \\
\hline $\begin{array}{l}\text { 11. Short exponentially weighted } \\
\text { moving average }\end{array}$ & EMA100 & $\sigma_{f, t+n}^{2}=\left(1-\lambda_{1}\right) \sum_{t=1}^{100} \lambda_{1}^{t-1}\left(r_{t}-\bar{r}\right)$ & $(12)$ \\
\hline 12. GARCH with $t$-distributed errors & GART & $\begin{array}{c}r_{t+1}=\mu+\varepsilon_{t+1}, \varepsilon_{t+1} \sim t_{k}\left(0, \sigma_{t+1}^{2}\right) \\
\sigma_{f, t+n}^{2}=\gamma_{0}+\varphi_{1} \varepsilon_{t}^{2}+\gamma_{2} \sigma_{t}^{2}\end{array}$ & (13) \\
\hline 13. Multivariate GARCH & MGAR & See text for model description & - \\
\hline
\end{tabular}

Notes: Forecast equations are given for $n=1$ step ahead, and recursions can easily be computed from these for the $2,3, \ldots, 20$ step-ahead forecasts. The model order $p$ for ARAIC is determined individually for each forecast iteration by the minimization of Akaike's information criterion, with maximal lag 5. All model parameters are estimated using quasi-maximum likelihood. The exponentially weighted moving average coefficients $\left(\lambda_{i}\right)$ are chosen to produce the best fit by minimizing the sum of the squared in-sample forecast errors.

on day $t$ is $r_{t}^{2}$, and it is this value that would be used as an input to the mean squared error calculation, or as the dependent variable in a Fair-Schiller (1990)-type regression of actual volatilities on their forecasted values.

Whilst this method is simple and intuitively plausible, Andersen and Bollerslev (1998, hereafter $\mathrm{AB})$ suggest that 'same-frequency' squared returns are an unbiased but extremely noisy measure of the latent volatility factor which underlies financial asset return movements. $\mathrm{AB}$ show that $\mathrm{a}$ 
much better approximation to the latent volatility factor can be obtained by summing the squares of higher frequency returns. For example, a superior estimate of volatility on day $t$ to $r_{t}^{2}$ is given by

$$
r_{t}^{2 *}=\sum_{j=1}^{m} r_{t-1+(j / m)}^{2}
$$

where $m$ is an intra-day sampling frequency, such as 8 for hourly data. ${ }^{6}$

Unfortunately, for many applications, the usefulness of this method is limited by the lack of availability of a sufficiently long span of higher-frequency returns. In the present paper, however, our analysis focuses upon daily, weekly, bi-weekly, and monthly forecasts. For the latter three horizons, two methods of calculating ex post volatility are available, both of which are employed in this study. The first of these ex post measures, which may usefully be termed the traditional measure, is to use weekly, bi-weekly or monthly squared returns. ${ }^{7}$ The second method, would be to take the daily returns, square them, and sum them over the relevant (5-, 10-, or 20-day) horizon. ${ }^{8}$ As $\mathrm{AB}$ note, it is not necessarily the case that the two ex post measures will give the same model rankings, let alone the same values of the error measures. Thus a comparison of model rankings under the two approaches is a relevant question for research, which this paper makes the first attempt to address.

\section{Value at Risk calculation}

Given the voluminous literature which almost unquestioningly evaluates volatility forecasts using standard loss functions, three sensible questions to ask are first, what are volatility forecasts useful for, second, what is an appropriate loss function given this usage, and finally, will alternative loss functions lead to approval of the same or similar models? Some answers to the first of these questions are provided in the introduction to this paper. One use of volatility predictions, which has grown substantially in importance over recent years, is as an input to financial risk management. In this paper, we thus employ a relevant 'risk management' loss function, which is based upon the calculation of an institution's value at risk, as defined above in the first section. Specifically, we calculate VaR for three individual assets by calculating the following quantity:

$$
\operatorname{VAR}_{t}^{i}(N, \alpha)=\left[F_{t, N}^{i}\right]^{-1}\left(\frac{\alpha}{100}\right)
$$

where $V A R_{t}^{i}$ is the Value at Risk for a given asset at time $t$, determined from model $i$ (where $i=1,13$ are the models as defined above), $N$ is the investment horizon, $\left[F_{t, N}^{i}\right]^{-1}$ is a cumulative distribution function (cdf) and $\alpha$ is a percentage significance level. The cdf employed in this paper is that of a normal distribution.

A limiting assumption of the analysis in many empirical papers in risk management is the standard assumption of normality, for it is well known that asset returns are not Gaussian. However, the normal approximation is extremely widely used in the risk management field. Fat-tailed return distributions will lead the delta-normal model to understate the true value at risk (see Jorion, 1996 or Huisman et al., 1998). For example, a 5\% daily loss is observed to occur approximately once

\footnotetext{
${ }^{6}$ Assuming, of course, that 8 hourly observations are available from the financial market concerned.

${ }^{7} \mathrm{So}$, for example, the volatility for weekly returns would be given by $r_{t}^{2}=\left[\ln \left(P_{t} / P_{t-5}\right)\right]^{2}$.

${ }^{8}$ Obviously for the 1-day horizon, both methods will yield the same ex post measure.
} 
every two years, while if returns were normally distributed, such a change would be expected only once every 1000 years (Johansen and Sornette, 1999). A number of methods to incorporate the fat tails have been proposed, most importantly the use of extreme value distributions for returns (e.g. Embrechts et al., 1999). However, we continue to employ the normality assumption since other distributional approaches usually do not directly employ a volatility estimate. Therefore our purpose of comparing between volatility forecasts when used for risk management would be lost.

We employ both the $1 \%$ and $5 \%$ levels of significance. The former level has been selected by the Basle Committee (1996) as the focus of attention, although the first percentile of a distribution is more difficult to estimate than the fifth, and thus the latter is the quantity which many securities firms wish to employ (see JP Morgan, 1996). The VaR corresponding to 5\% may be defined as that amount of capital, expressed as a percentage of the initial value of the position, which will be required to cover $95 \%$ of probable losses. In the case of the normal distribution, this quantity may be calculated as

$$
V A R_{t}^{i}(N, 5 \%)=1.645 \sigma_{t, N}^{i}
$$

where $\sigma_{t, N}^{i}$ is the square root of the conditional variance forecast, made at time $t$ for forecast horizon $N(N=1,5,10,20)$. We thus forecast volatility for some future period $(t, N)$ and hence we calculate the amount of capital required to cover expected losses on $95 \%$ or $99 \%$ of the investment horizons. The $95 \%$ confidence level is employed by the popular RiskMetrics ${ }^{\mathrm{TM}}$ risk measurement software, while the regulators require capital to cover $99 \%$ of losses. ${ }^{9}$

The calculation of the value at risk estimates for the individual assets is achieved by following the steps outlined above. In the case of the portfolio, however, for all forecasting models except the multivariate GARCH (that is, models 1-12 in Table II), we employ a method known as the 'full valuation approach'. This simply involves the aggregation of the components and the calculation of the portfolio return at each point in time. In this case, the resulting portfolio return series is modelled in the same way as the individual component assets.

An alternative approach is known as the 'volatilities and correlations' method, which has been popularized by JP Morgan (1996). Here, the portfolio value at risk is estimated using the volatilities of the individual assets which form the MCRR, and the correlations between their returns. The portfolio value at risk may be written

$$
M C R R_{P}=\sqrt{\begin{array}{c}
a^{2} M C R R_{A}^{2}+b^{2} M C R R_{B}^{2}+c^{2} M C R R_{C}^{2} \\
+2 a b \rho_{A B} M C R R_{A} M C R R_{B} \\
+2 a c \rho_{A C} M C R R_{A} M C R R_{C} \\
+2 b c \rho_{B C} M C R R_{B} M C R R_{C}
\end{array}}
$$

where $A, B$, and $C$ denote the bond, stock and commodities series respectively, and $a=b=c=$ $1 / 3$. We adopt this approach when using the multivariate GARCH model, but instead of using the time-invariant volatility and correlation estimates, we instead use the relevant forecasts of the conditional variances and covariances from the MGARCH model in (6) to derive the VaR.

\footnotetext{
${ }^{9}$ In fact, the $99 \%$ VaR is multiplied by a 'scaling factor', which is usually 3, so that the actual coverage rate is considerably higher than $99 \%$. We do not employ the regulatory scaling factor in our analysis, so as to focus upon forecast adequacy. Multiplying the estimated VaR by 3 has the effect of rendering the forecasted VaRs virtually indistinguishable from one another, since the implied coverage rate is now more than $99.99 \%$.
} 


\section{Risk management-based forecast evaluations}

In this paper, we employ three methods for determining the adequacy of the volatility forecasts that are used as an input to the value at risk calculation. All methods essentially require the calculation of VaR, and then assuming that the securities firm had employed this much capital, the methods track the actual realized losses during an out-of-sample period. The simplest approach to determining model adequacy in the risk management framework is to calculate the time until first failure (TUFF), defined as the first observation in the hold-out sample where the capital held is insufficient to absorb that period's loss, and derived as follows. Following Kupiec (1995), let $p$ denote the realized probability of observing the first failure of the model in period $V$, and letting $\tilde{R}$ be a random variable that denotes the number of observations until the first failure is recorded, then we may write

$$
\operatorname{Pr}(\tilde{R}=V)=p(1-p)^{V-1}
$$

Then $\tilde{R}$ has a geometric distribution with an expected value of $1 / p$. This quantity can be interpreted as the expected number of observations until the first failure is observed. In the cases of interest in this paper, if the actual proportion of failures were $5 \%$ and $1 \%$ respectively, then the time until first failure would be 100 and 20 steps respectively. If we now let $p^{*}$ denote the probability of failure under the null hypothesis, then the following likelihood ratio test can be established:

$$
\operatorname{TUFF}(V, p *)=-2 \log \left[p *(1-p *)^{V-1}\right]+2 \log \left[\frac{1}{V}\left(1-\frac{1}{V}\right)^{V-1}\right]
$$

which is $\chi^{2}(1)$ under the null. Given the appropriate critical value, it is possible to derive a $95 \%$ confidence interval for TUFF of $(6,439)$ for the $1 \%$ VaR and $(-, 87)$ for the $5 \%$ VaR. ${ }^{10}$ The confidence intervals can be interpreted as follows. If VaR determined using a $1 \%$ significance level fails before the 6th observation, we can reject at the 5\% level the null hypothesis that the model is adequate to cover losses on $99 \%$ of occasions. On the other hand, if the actual TUFF is greater than 439 , then we would conclude that the model was leading to too high a value at risk, and therefore that the model was not failing as quickly as would be expected given the nominal $1 \%$ probability of failure.

It is perhaps worth noting that it is desirable from the point of view of the bank or securities firm concerned, for the calculated value at risk to be neither too large nor too small. A value at risk set too low could imply that the bank does not have sufficient capital to cover future losses, leading at best to regulatory scrutiny, and an increase in the scaling factor (resulting in a substantial increase in the capital requirement), and at worst to financial distress and possible company failure. Conversely, a VaR set too high, so that it covers more than the nominal percentage of horizons (e.g. an estimated 5\% daily VaR which is actually sufficient to cover $99.9 \%$ of the out of sample periods), probably implies that the firm is tying up too much of its capital unnecessarily in an unprofitable fashion. ${ }^{11}$

Whilst intuitive and simple to calculate, TUFF has obvious flaws as an evaluation metric. First, it is clearly not using much information from the sample, since all observations after the first failure are ignored, resulting in the test being over-sized. Thus, if the start of the out-of-sample

\footnotetext{
${ }^{10}$ It is not possible to establish a lower limit for the $5 \%$ VaR interval.

${ }^{11}$ Particularly in view of the regulatory scaling factor, which multiplies the firm's own VaR estimate by at least 3.
} 
period occurs at a time of exceptional market turbulence, a model which may have been perfectly adequate for the rest of the sample and incurring no further failures, would be rejected. Second, the TUFF statistic consequently has low power to reject models which are not adequate-this is clearly evidenced by the wide confidence intervals for TUFF presented above. For example, a 99\% nominal coverage rate is expected to result in first failure at observation 100, but even if an exceedence of the VaR is recorded as early as observation 7 , we cannot reject the underlying model at the $1 \%$ level; thus TUFF will have low ability to discriminate between volatility forecasts from different models.

Another simple method for determining model adequacy within the risk management framework is simply to calculate the percentage of times that the calculated VaR is insufficient to cover the actual losses, during the rolling out-of-sample period. A good model would be one whose proportion of out-of-sample exceedences is close to the nominal value of (one minus coverage probability) $\%$ assumed (5\% or $1 \%$ ). We can also formulate a likelihood ratio test for the proportion of failures, in similar vein to (19) above. The probability of observing $x$ failures in an actual sample of independent observations of size $K$ will be distributed binomially, leading to the following test statistic distributed $\chi^{2}(1)$ under the null:

$$
U C F\left(K, x, p^{*}\right)=-2 \log \left[\left(1-p^{*}\right)^{K-x}\left(p^{*}\right)^{x}\right]+2 \log \left[\left(1-\left(\frac{x}{K}\right)\right)^{K-x}\left(\frac{x}{K}\right)^{x}\right]
$$

with notation as above. For ease of interpretation of the results, models are also ranked in the following way. We assume that any model which has a percentage of exceedences in the rolling holdout sample which is greater than the nominal threshold should be rejected as inadequate. Therefore, the lowest ranking models (classified as worst) are those which have the highest percentage of failures greater than the nominal value.

When these models have been exhausted, we assume further that any model which generates far fewer exceedencess than the expected number is less desirable than a model which generates closer to the nominal number. Thus the best models under this loss function are those which generate less than, but closest to, the assumed coverage rate. ${ }^{12}$

\section{RESULTS}

\section{Statistical evaluation criteria}

The results for the volatility forecasts under standard statistical evaluation methods (percentage of over-predictions, mean squared error, and mean absolute error) are presented in Tables III to VI for the government bond, FTA All-Share, commodities and portfolio series respectively.

Considering first the one-step-ahead (1-day) forecast horizon, a number of important features emerge. As one might anticipate, the random walk in volatility model produces roughly equal numbers of over-and under-predictions of realized volatility measured by the squared daily returns. On the other hand, all models over-predict volatility on average $70 \%$ of the time, except for the two EWMAs which over-predict more frequently than they under-predict. In all other respects, the random walk in volatility produces uniformly poor forecasts.

${ }^{12}$ Of course, this could be replaced by a simpler symmetric or any other loss function if the user desired. 


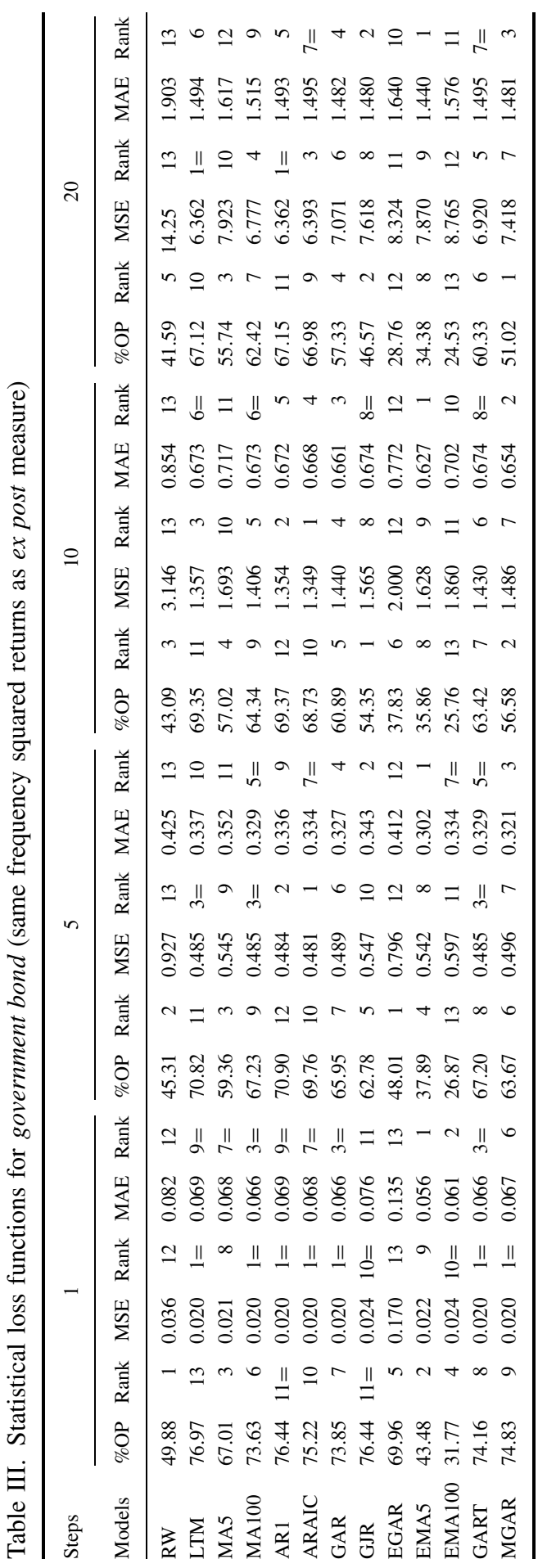

Copyright (C) 2003 John Wiley \& Sons, Ltd.

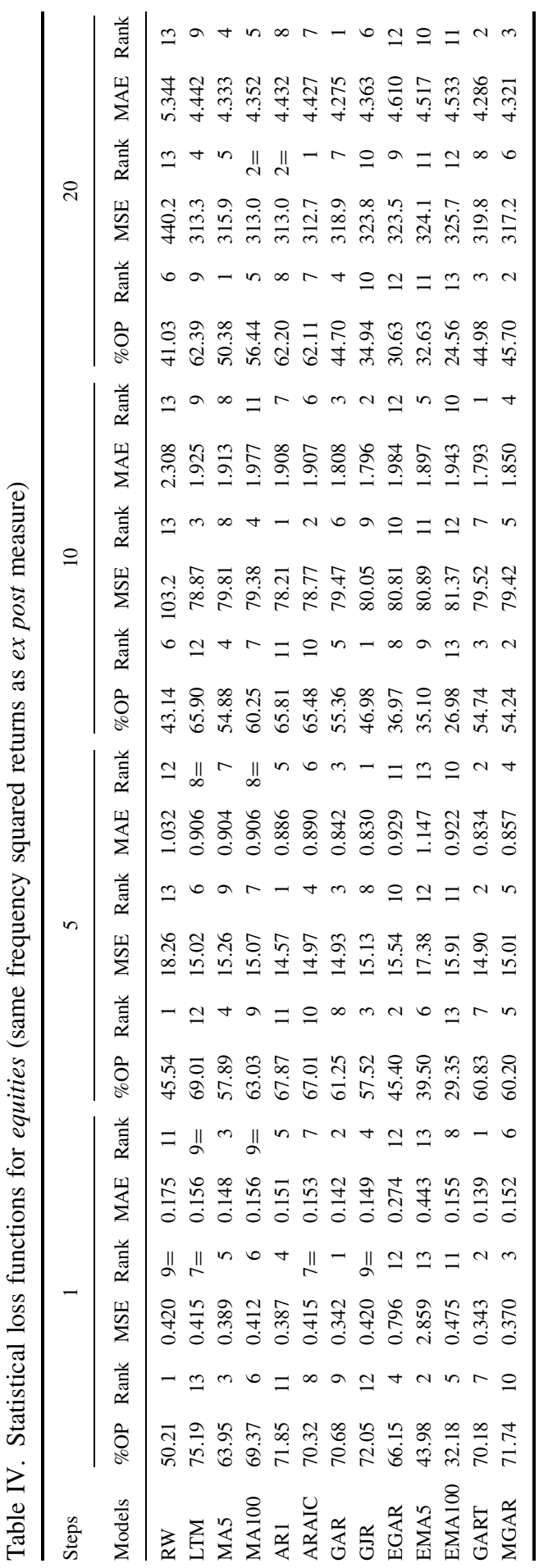

J. Forecast. 22, 1-22 (2003) 


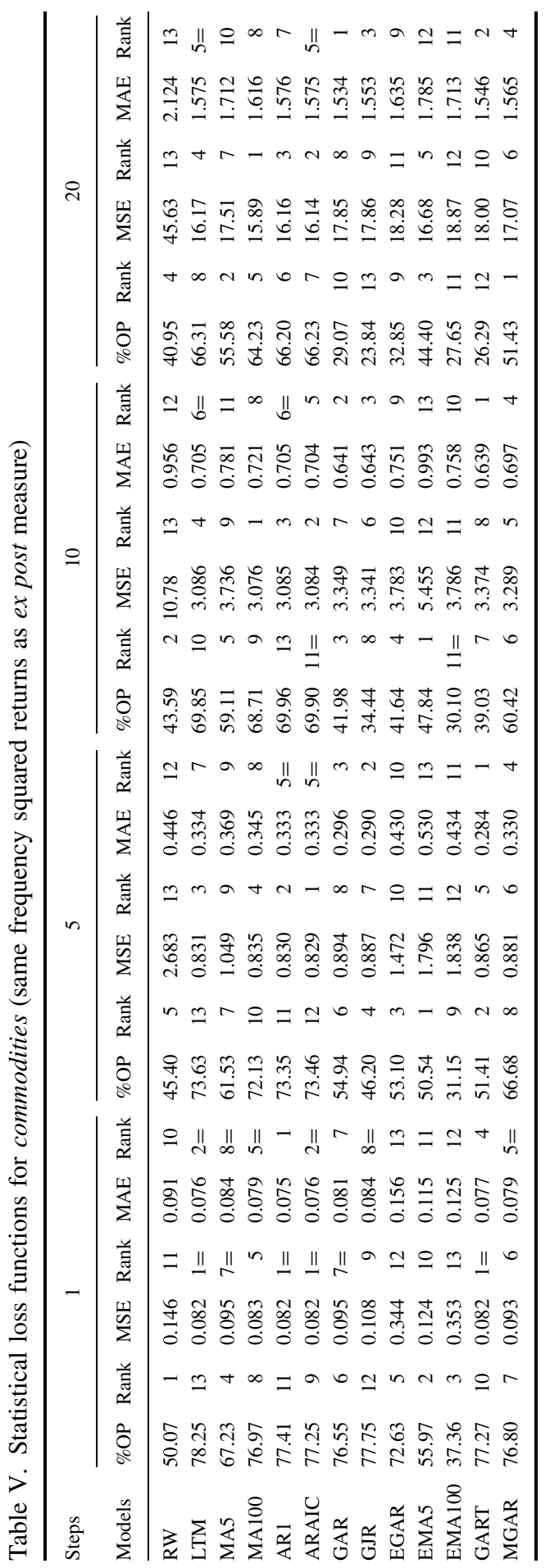

Copyright (C) 2003 John Wiley \& Sons, Ltd.

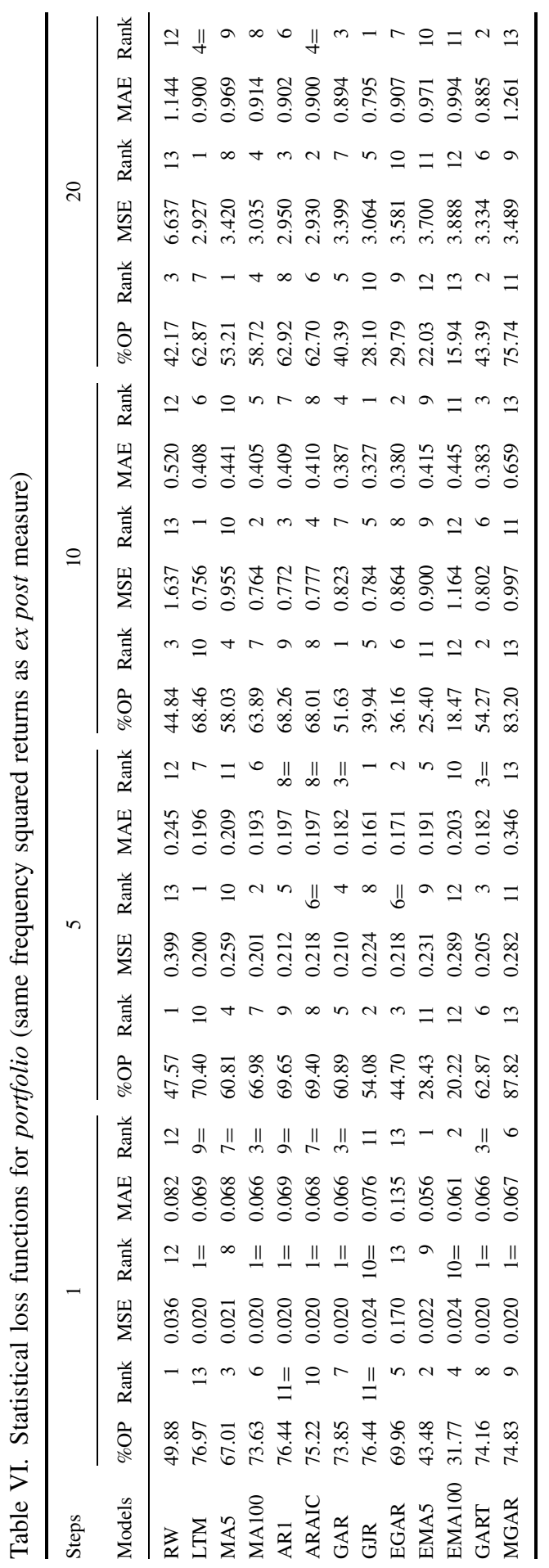

J. Forecast. 22, 1-22 (2003) 
No clear 'winners' emerge at the 1-day horizon, with different models being preferred for each series. MSE is clearly not a good discriminator at the top end, with many models ranked equally as the best. MAE, on the other hand, selects EWMA models for the bond and portfolio series, while for the share and commodity series, the GJR and autoregressive volatility models are preferred. In terms of the least accurate next-day forecasting models, the random walk in volatility and EGARCH models emerge as the worst performers, followed by the EWMAs for commodities and shares, although the latter proved the most accurate for the other two series.

An extension of the forecast and investment horizon to the one (trading) week, two-week, and onemonth range does not markedly alter the relative model rankings, although the broad disagreement between criteria for a given series and model is still apparent. For example, the autoregressive model, which ranks only seventh by MSE for the equities series at the one-day horizon, ranks first when the investment horizon is extended to one month.

However, as Andersen and Bollerslev (1998) have shown, the use of low-frequency squared returns is often not a useful way to evaluate volatility forecasts, and it is quite possible that when sums of higher-frequency squared returns are used instead as the ex post volatility measure, not only the values of the error measures but also the model rankings could change substantially. Thus for the 5-, 10-, and 20-day periods we also evaluate the forecast accuracies using the sum of squared daily returns. Results are presented for the bond, share, commodities, and portfolio series in Tables VII to X respectively. ${ }^{13}$ Comparing the results for the low-frequency squared returns versus the high-frequency sums of squared returns, we note first that the values of the error measures are as expected reduced considerably. ${ }^{14}$

The GARCH model with $t$-distributed errors now emerges as the clear winner, producing the most accurate forecasts according to MAE, for three of the four series (bonds, stocks, and the portfolio). Only for the commodities return series does GARCH- $t$ perform poorly. For the latter series, the long-term mean and autoregressive volatility models prove to be the best under both squared and absolute error measures. Interestingly, the worst models seem invariant to both the use of a same-frequency or higher-frequency ex post measure, and to whether the errors are squared or the absolute values taken; a bad model appears to be a bad model whatever. Models which fit into this category are the random walk in volatility, the exponential GARCH, and the exponentially weighted moving average model.

\section{Risk management evaluation criteria}

The corresponding evaluations for the forecasts when used in a risk management context are given in Tables XI to XVIII. Volatility forecasts can be employed for the production of $99 \%$ and $95 \%$ nominal coverage rates for the value at risk estimates. In other words, forecasts are generated in respect of the amount of capital required to cover expected losses on $99 \%$ and $95 \%$ of days respectively. The results for these two sets of nominal coverage rates are provided in Tables XI to XIV and XV to XVIII respectively for the 1-day, 1-week, 2-week and 1-month horizons. Three statistics are presented in each table - the time until first failure (TUFF), the proportion of failures (FT), and the test statistic associated with whether this proportion of failures is significantly higher than the nominal rate (UCF). Also given are the model rankings according to FT and $\mathrm{UCF}^{15}$ as described above.

\footnotetext{
${ }^{13}$ Of course, the results for the one-step-ahead evaluations will be identical to those of Tables III to VI.

${ }^{14}$ Mean squared errors are reduced by roughly an order equivalent to the forecasting horizon, while absolute errors are reduced by a factor of around two for all horizons.

15 The rankings according to FT and UCF will, of course, by definition be identical.
} 


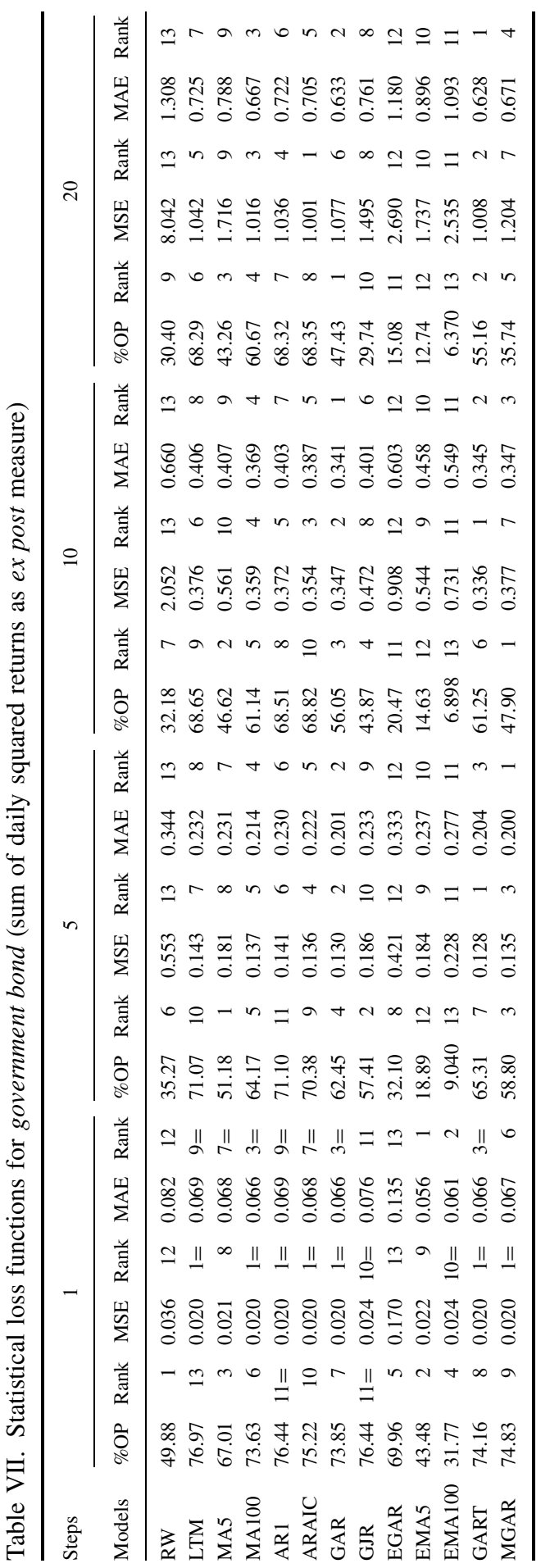

Copyright (C) 2003 John Wiley \& Sons, Ltd.

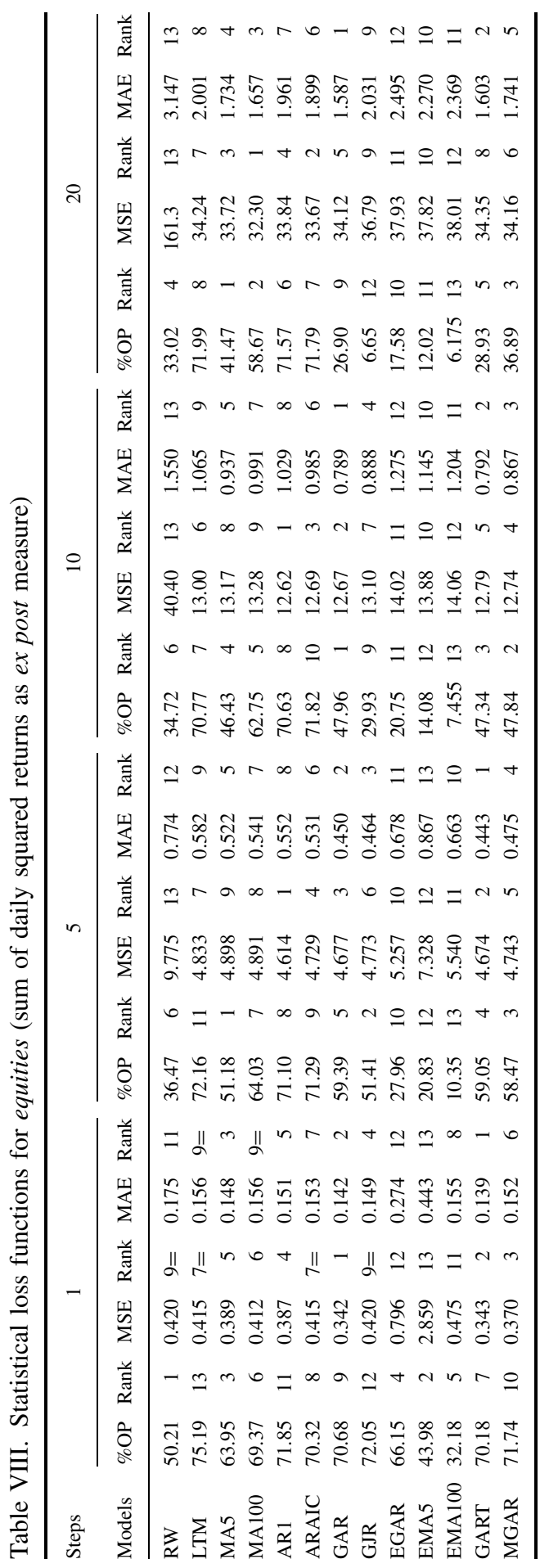

J. Forecast. 22, 1-22 (2003) 


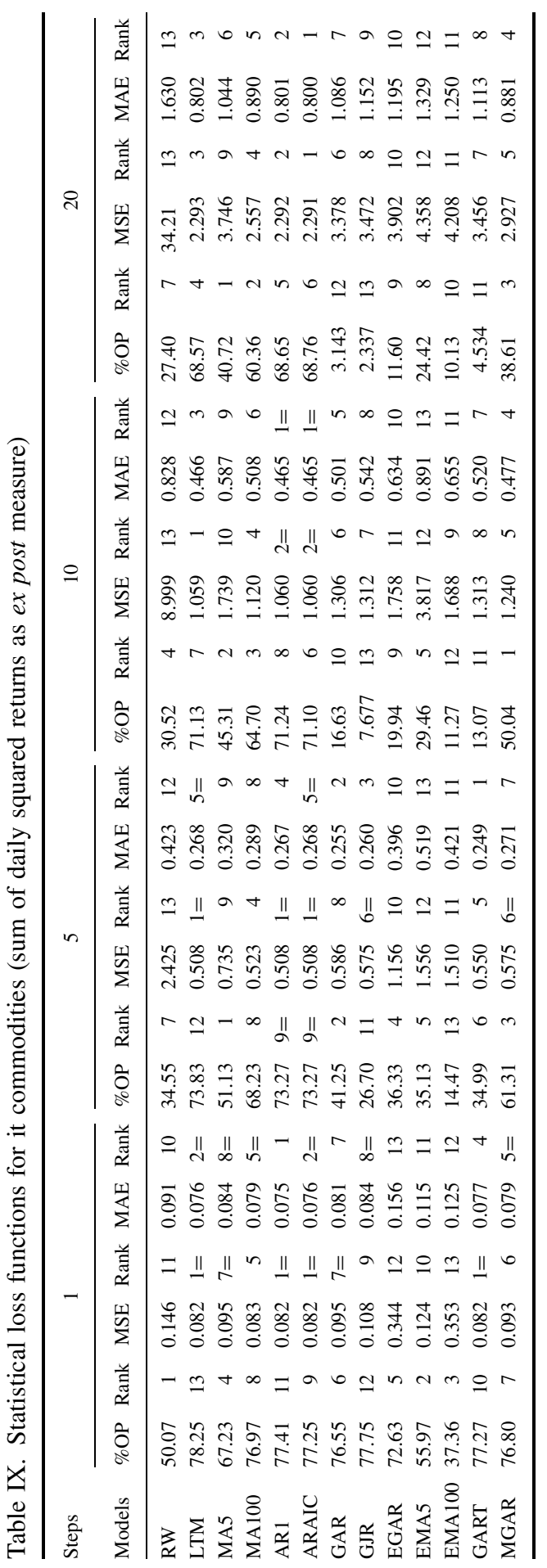

Copyright (C) 2003 John Wiley \& Sons, Ltd.

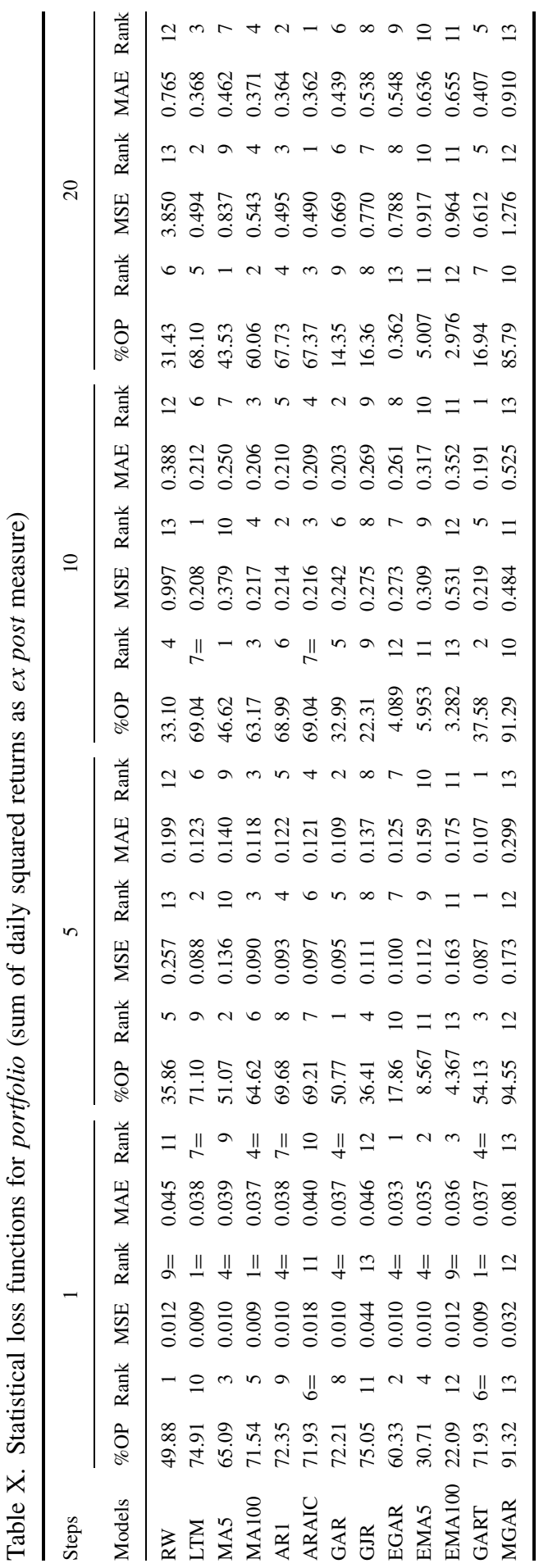

J. Forecast. 22, 1-22 (2003) 


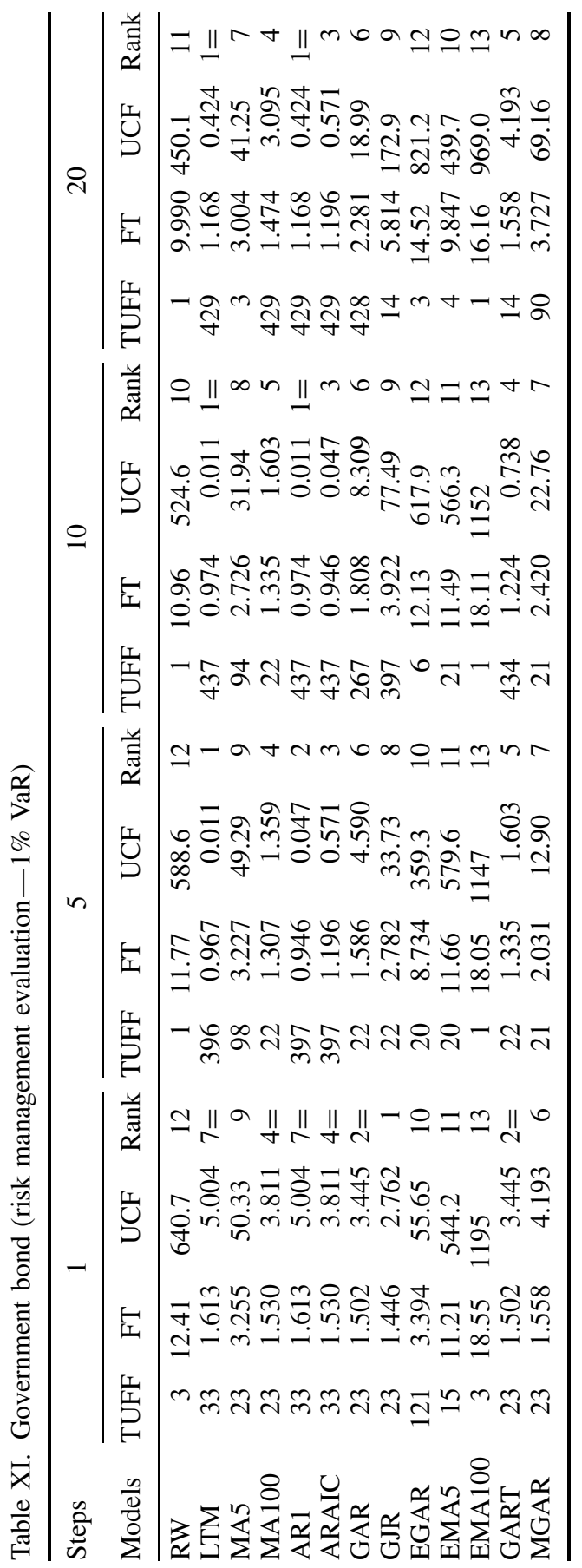

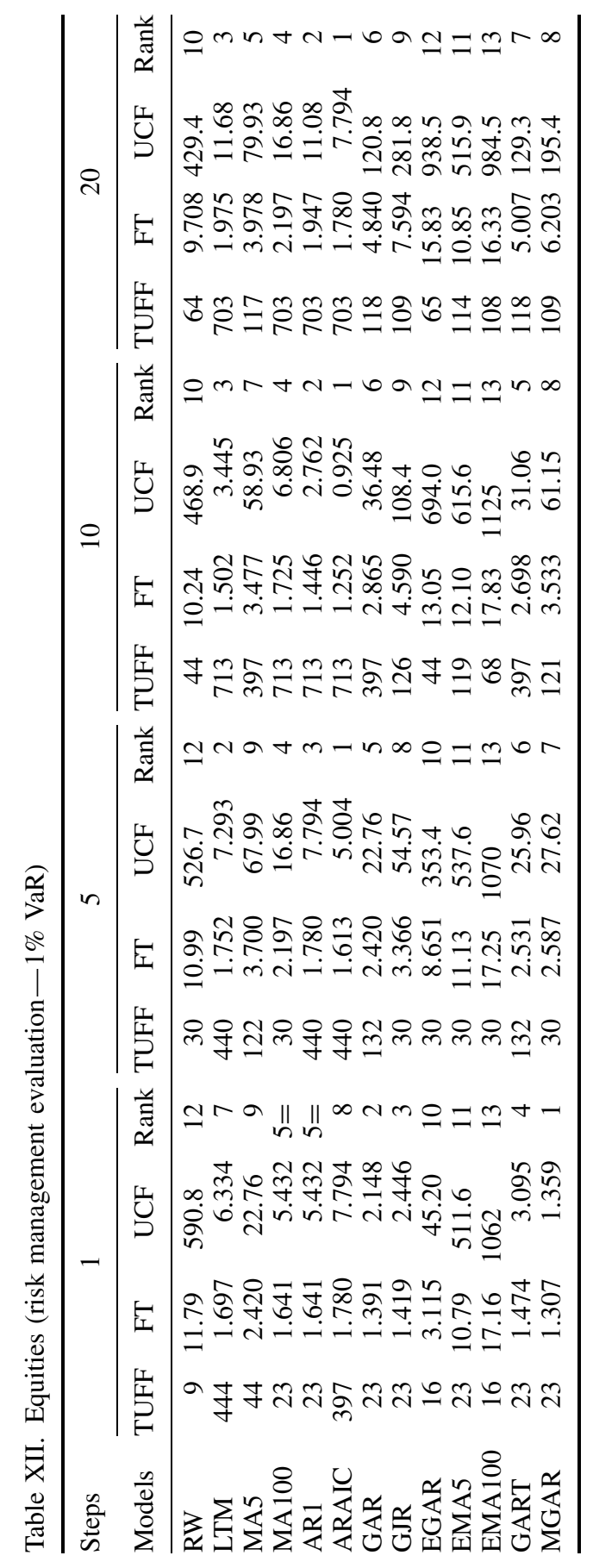




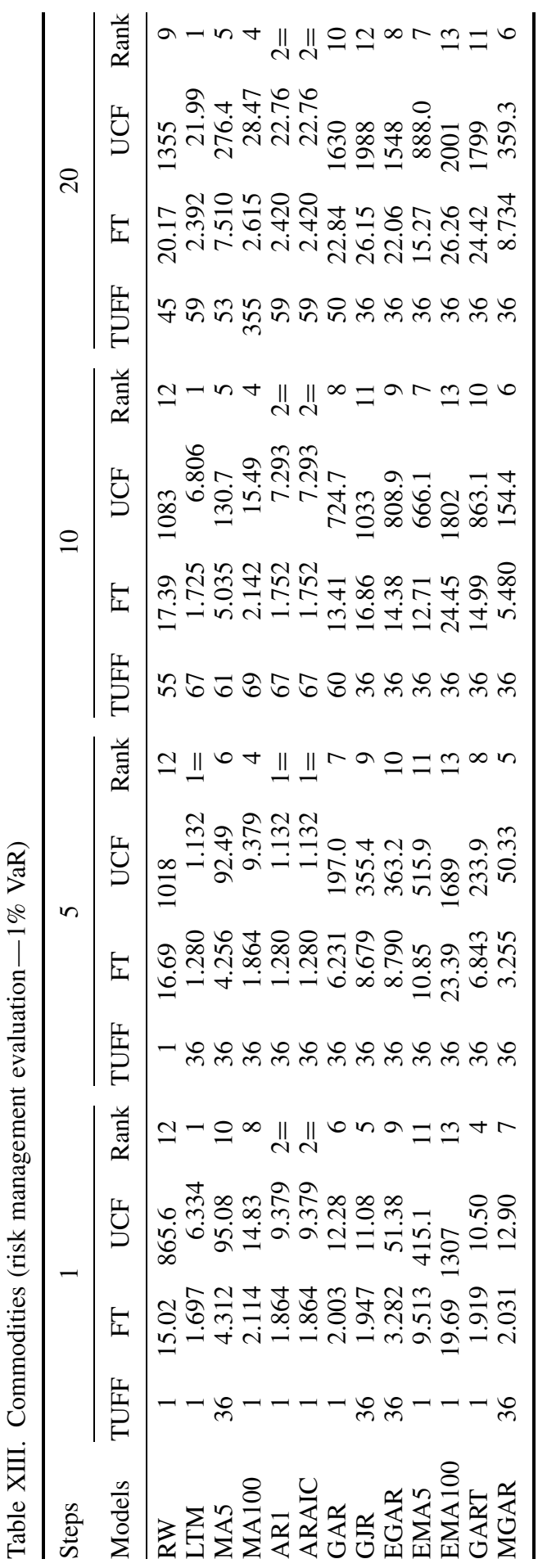

Copyright (C) 2003 John Wiley \& Sons, Ltd.

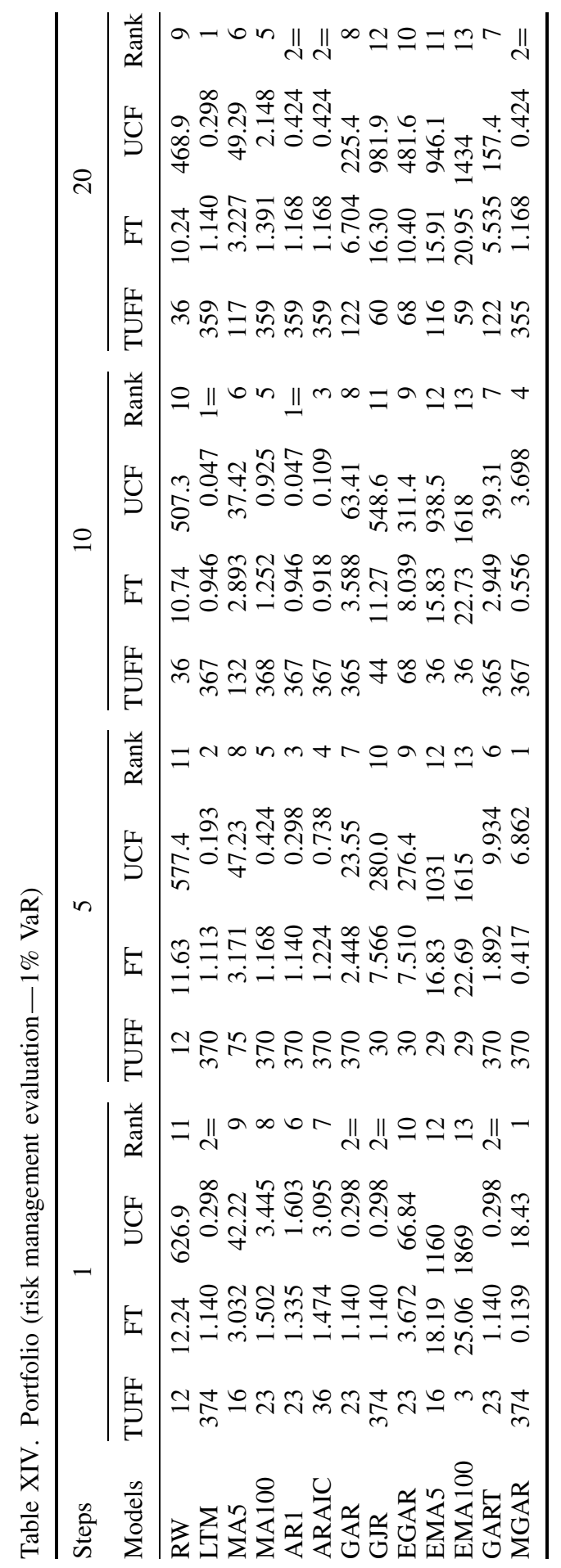

J. Forecast. 22, 1-22 (2003) 


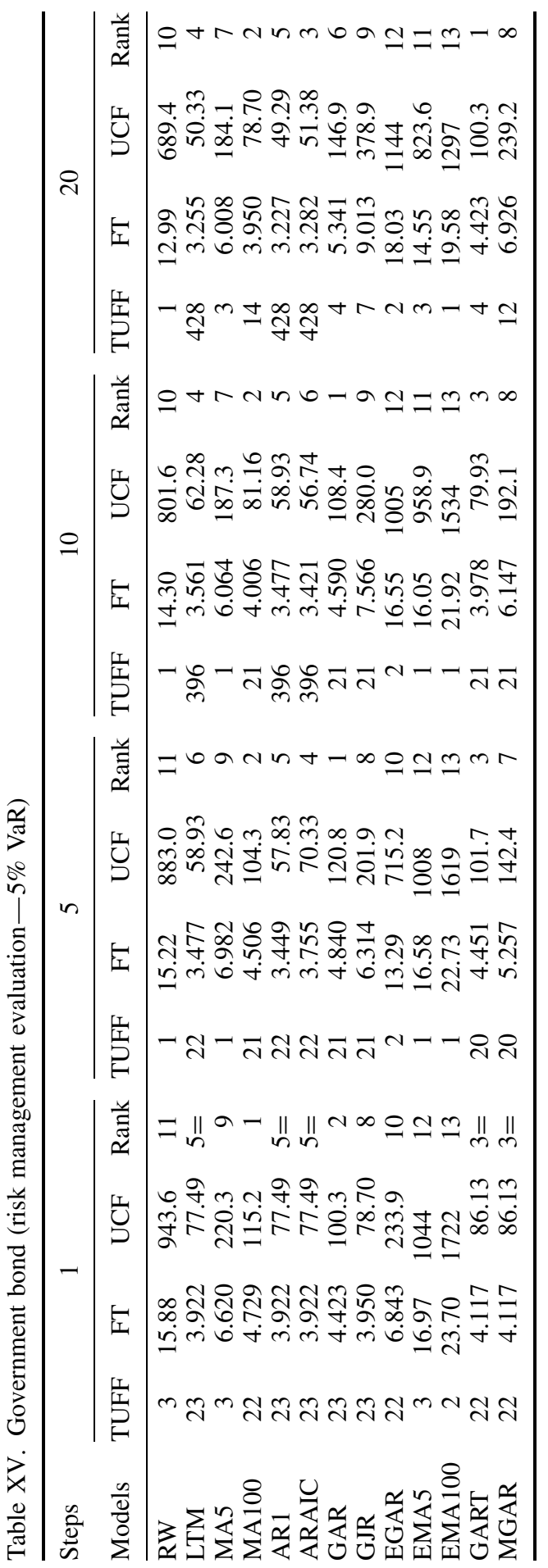

Copyright (C) 2003 John Wiley \& Sons, Ltd.

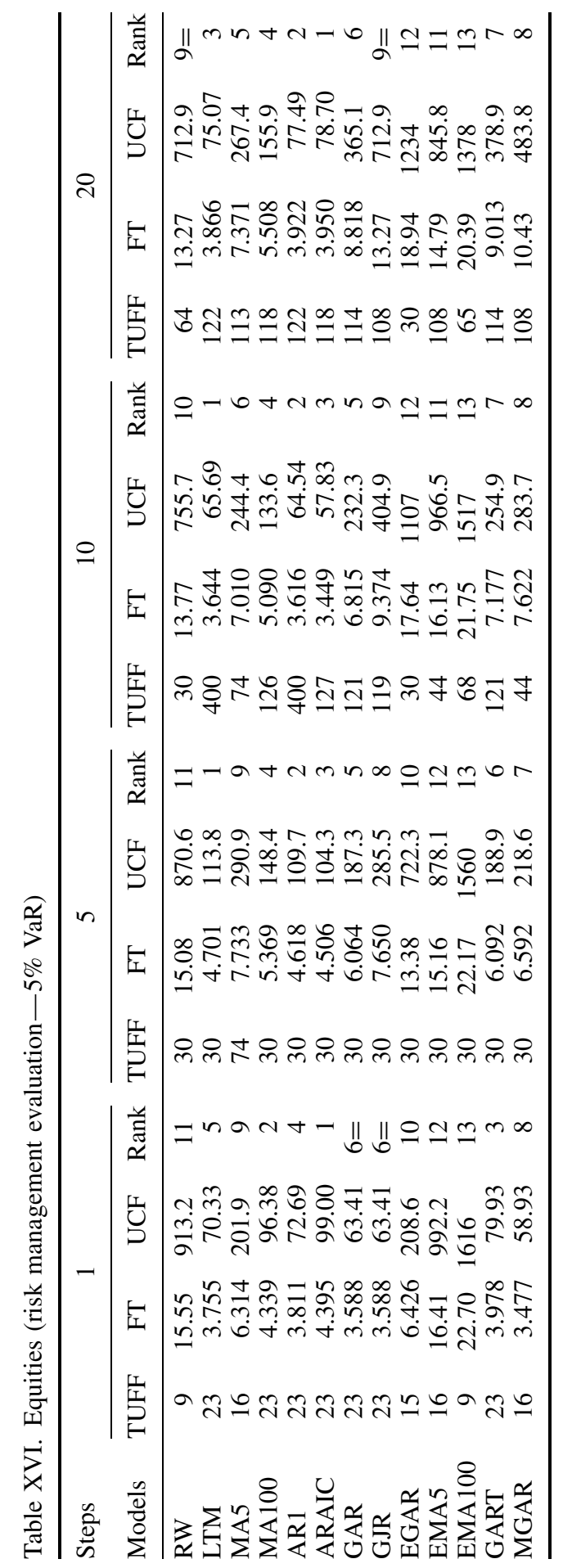

J. Forecast. 22, 1-22 (2003) 


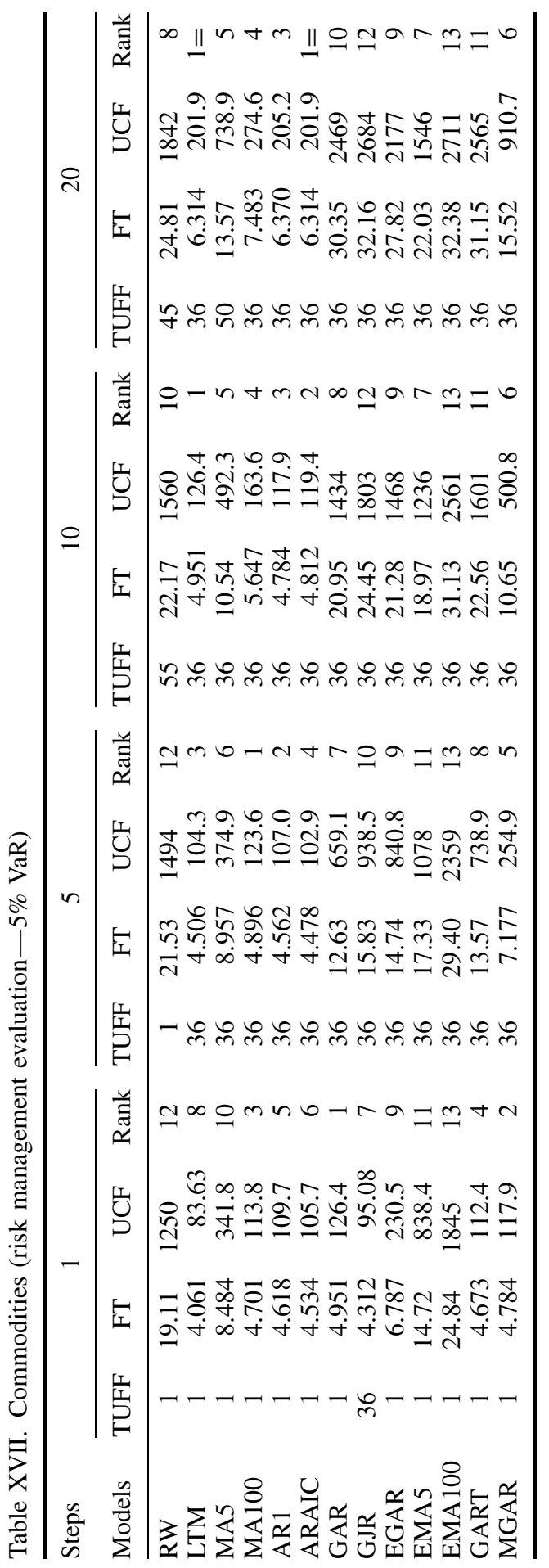

Copyright (C) 2003 John Wiley \& Sons, Ltd.

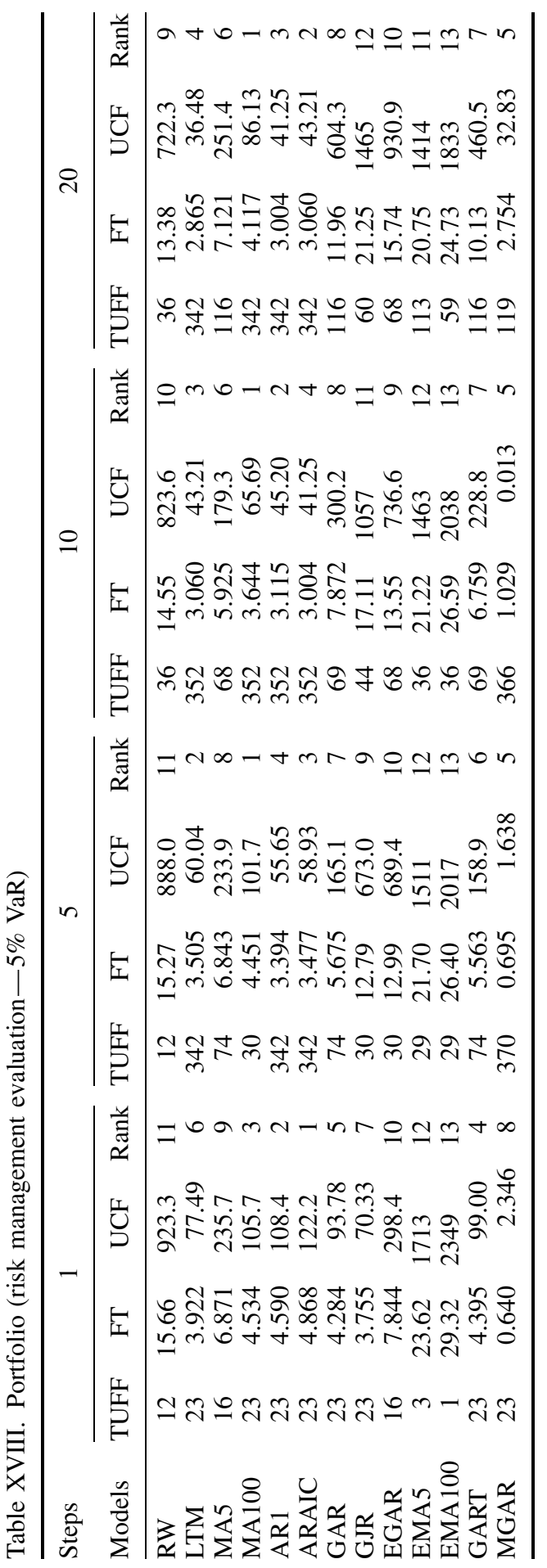

J. Forecast. 22, 1-22 (2003) 
The first point to note is that if the objective is to cover $99 \%$ of future losses, then almost none of the models are adequate. The proportion of exceedences for the bond, share and commodity assets is always considerably in excess of $1 \%$ - typically $1.4-2 \%$. Thus for example, even the best model at the 1-day horizon for the commodities data, which is the long term mean, has nearly $70 \%$ more violations of value at risk in the hold-out sample than would be expected under the null. Also for this series, the majority of models have a TUFF statistic that takes on a value of one - that is, they fail at the first observation! Almost none of the models for any of the four asset classes makes it to the hundredth observation, the expected time until first failure. Consequently, the UCF statistic rejects all models for all individual asset series at all horizons.

Matters are improved somewhat for the portfolio of assets, presumably as a result of the benefits of diversification in reducing the number of extreme observations that lead to an exceedence of the $\mathrm{VaR}$. The typical proportion of exceedences is reduced to around $1.2 \%$, and although only the multivariate GARCH model has fewer than $1 \%$ exceedences, several models are acceptable according to the UCF test statistic. Similar patterns are revealed at the 1-day and longer horizons. The models fare much better when only $95 \%$ coverage is desired; more than half of the models achieve their nominal rate. In terms of model rankings, the long-term mean and the linear regression in volatility models seem preferable, although again, there is no uniformly most accurate model. The GARCH model seems to provide reasonably accurate VaR estimates, evidenced by its actual coverage rate being close to the nominal rate, although there is a tendency to over-estimate the VaR, a result also observed by Brooks, Clare and Persand (2000).

\section{CONCLUSIONS}

This paper has sought to re-examine the volatility forecasting literature in the context of a relatively new use of volatility forecasts - for financial (market) risk assessment. A number of our results are worthy of further note. First, the gain from using a multivariate GARCH model for forecasting volatility, which has not been previously investigated, is minimal. This result is true both under standard statistical and risk management evaluation measures. Given the complexity, estimation difficulties, and computer-intensive nature of MGARCH modelling, we conjecture that unless the conditional covariances are required, the estimation of multivariate GARCH models is not worth while. In the context of portfolio volatility, more accurate results can be obtained by aggregating the portfolio constituents into a single series, and forecasting that, rather than modelling the individual component volatilities and the correlations between the returns.

Second, it appears that some models are poor performers irrespective of both the series on which they are estimated and the loss function used to evaluate their forecasts. The random walk in volatility, the EGARCH and to a lesser extent the EWMA models, fall into this category.

When it comes to selecting the 'best' model for forecasting, however, the particular evaluation measure employed plays a predominant role. Whilst there seems to be little difference in the model rankings when the ex post measure is changed from low-frequency to high-frequency squared returns, the differences between rankings under statistical and risk management procedures are substantial. Although generalizing across data series (asset classes) and investment horizons is difficult, overall the statistical measures preferred the GARCH(1,1) model over simpler techniques and over its extensions and variants. On the other hand, when evaluated in the context of VaR estimates which achieve an appropriate out-of-sample coverage rate, the simplest models, such as the long-term mean (historical average) or the autoregressive volatility model, are preferred. We 
thus concur with Dacco and Satchell (1999) in arguing that the choice of loss function can have an over-riding effect upon volatility forecasting accuracies; thus the debate on superior volatility forecasting models should be considered far from resolved.

\section{ACKNOWLEDGEMENTS}

The authors would like to thank an anonymous referee for useful comments on a previous version of this paper. The usual disclaimer applies.

\section{REFERENCES}

Akgiray V. 1989. Conditional heteroskedasticity in time series of stock returns: evidence and forecasts. Journal of Business 62: $55-80$.

Alexander CO, Leigh CT. 1997. On the covariance models used in Value at Risk models. Journal of Derivatives 4: 50-62.

Andersen T, Bollerslev T. 1998. Answering the skeptics: yes, standard volatility models do provide accurate forecasts. International Economic Review 39: 885-905.

Basle Committee on Banking Supervision. 1988. International Convergence of Capital Measurement and Capital Standards July.

Bollerslev T, Chou RY, Kroner KF. 1992. ARCH modelling in finance: a review of the theory and empirical evidence. Journal of Econometrics 52: 5-59.

Bollerslev T, Engle RF, Wooldridge JM. 1988. A capital asset pricing model with time-varying covariances. Journal of Political Economy 96: 116-131.

Brailsford TJ, Faff RW. 1996. An evaluation of volatility forecasting techniques. Journal of Banking and Finance 20: 419-438.

Brooks C. 1998. Forecasting stock return volatility: does volume help? Journal of Forecasting 17: $59-80$.

Brooks C, Clare AD, Persand G. 2000. A word of caution on calculating market-based minimum capital risk requirements. Journal of Banking and Finance 14(10): 1557-1574.

Brooks C, Henry OT, Persand G. 2002. Optimal hedging and the value of news. Journal of Business 75(2): 333-352.

Brooks C, Persand G. 2000a. Value at Risk and market crashes. Journal of Risk 2(4): 5-26.

Brooks C, Persand G. 2000b. Lies, damned lies and Value at Risk estimates. Risk 13(5): May, 63-66.

Dacco R, Satchell S. 1999. Why do regime-switching models forecast so badly? Journal of Forecasting 18: $1-16$.

Day TE, Lewis CM. 1992. Stock market volatility and the information content of stock index options. Journal of Econometrics 52: 267-287.

Dimson E, Marsh P. 1990. Volatility forecasting without data snooping. Journal of Banking and Finace 14: 399-421.

Dowd K. 1998. Beyond Value at Risk: The New Science of Risk Management. Wiley: Chichester.

Embrechts P, Resnick SI, Samorodnitsky G. 1999. Extreme value theory as a risk management tool. North American Actuarial Journal 3: 30-41.

Fair RC, Shiller RJ. 1990. Comparing information in forecasts from econometric models. American Economic Review 80: 375-389.

Franses PH, van Dijk D. 1996. Forecasting stock market volatility using non-linear GARCH models. Journal of Forecasting 15: 229-235.

Heynen RC, Kat HM. 1994. Volatility prediction: a comparison of the stochastic volatility, GARCH(1,1) and EGARCH $(1,1)$ models. Journal of Derivatives 2: 50-65.

Huisman R, Koedijk KG, Poqwnall RAJ. 1998. VaR-x: fat tails in financial risk management. Journal of Risk 1: $47-61$.

Copyright @ 2003 John Wiley \& Sons, Ltd.

J. Forecast. 22, 1-22 (2003) 
Jackson P, Maude DJ, Perraudin W. 1998. Testing Value at Risk approaches to capital adequacy. Bank of England Quarterly Bulletin 38: 256-266.

Johansen A, Sornette D. 1999. Critical crashes. Risk 12: 91-95.

Jorion P. 1996. Value at Risk: The New Benchmark for Controlling Market Risk. Irwin: Chicago, IL.

Morgan JP. 1996. Riskmetrics Technical Document 4th edn.

Kupiec P. 1995. Techniques for verifying the accuracy of risk measurement models. Journal of Derivatives 2: $73-84$.

Pagan AR, Schwert GW. 1990. Alternative models for conditional stock volatilities. Journal of Econometrics 45: $267-290$.

West KD, Cho D. 1995. The predictive ability of several models of exchange rate volatility. Journal of Econometrics 69: 367-391.

West KD, Edison HJ, Cho D. 1993. A utility-based comparison of some models of exchange rate volatility. Journal of International Economics 35: 23-45.

Authors' biographies:

Chris Brooks is Professor of Finance at the ISMA Centre, University of Reading, where he also obtained his $\mathrm{PhD}$. He has published over forty papers in leading academic and practitioner journals in finance, econometrics and economics, and is also author of the textbook Introductory Econometrics for Finance, published by Cambridge University Press.

Gita Persand is a Lecturer in Finance at the Department of Economics, University of Bristol. She obtained her PhD from the ISMA Centre, University of Reading. Her research interests are in the field of financial risk management, and she has published in outlets such as Journal of Business, Journal of Banking and Finance, and Journal of Risk.

Authors' addresses:

Chris Brooks, ISMA Centre, University of Reading, PO Box 242, Whiteknights, Reading RG6 6BA, UK.

Gita Persand, Department of Economics, University of Bristol, Bristol B58, 1TH, UK. 